Original Research Article

\title{
Prescribing pattern of ophthalmological medication in geriatric inpatients of a tertiary care hospital
}

\author{
Sudhindra Prathap A. ${ }^{1}$, Radhika M. S. ${ }^{1 *}$, Reethesh Kumar Rai ${ }^{2}$
}

${ }^{1}$ Department of Pharmacology, SDM College of Medical

Sciences and Hospital,

Dharwad, Karnatka, India

${ }^{2}$ Department of Pharmacology,

Mahamaya Rajkiya Allopathic

Medical College, Ambedkar

Nagar, Uttar Pradesh, India

Received: 10 February 2019

Accepted: 30 March 2019

*Correspondence to:

Dr. Radhika M. S.,

Email: drradhika78@gmail.com

Copyright: (C) the author(s), publisher and licensee Medip Academy. This is an openaccess article distributed under the terms of the Creative Commons Attribution NonCommercial License, which permits unrestricted noncommercial use, distribution, and reproduction in any medium, provided the original work is properly cited.

\begin{abstract}
Background: Older people are potentially at greater risk of medication error. Gaining insight into the prescribing pattern especially in eye diseases as they are a common problem in elderly, in order to identify prescribing related problems is the fundamental step in improving the quality of prescription and patient care.

Methods: Prescriptions fulfilling inclusion criteria were collected from hospital Medical record department (MRD) and analyzed using the World Health Organization (WHO) core prescribing indicators for rationality of prescriptions. Results: Among 811 prescriptions analysed, 52.7\% (428) were of male patients, those aged $60-70$ years were $77.2 \%$ (626) and patients with only cataract constituted $77 \%$ (625). Prescriptions with oral antibiotics were $57.1 \%$ (334); topical antibiotics were $35.8 \%$ (429) and topical analgesics $46.2 \%$ (553). Out of 1182 FDCs noted, $59 \%$ (479) were found to be rational and $34.6 \%$ (281) were from Essential Medicines List 2014. Only 2\% (61) drugs were prescribed using generic name while $64.06 \%$ (1606) of drugs were from the WHO Model List of Essential Medicines (April 2015). Average number of drugs per encounter was 3.7. Percentage of encounters with antibiotics was found to be $43.8 \%$ and no prescriptions with injections were noted.

Conclusions: Although usage of antibiotics and topical drugs was conforming to WHO recommended standards, there is a need to improve prescription pattern by using generic names and drugs from Essential Drug List.
\end{abstract}

Keywords: Drug utilization study, Eye diseases, Essential drug list, Geriatric, Ophthalmological medication, WHO prescribing indicators

\section{INTRODUCTION}

The elderly population is rapidly increasing worldwide. Their growth rate $(1.9 \%)$ is higher than general population $(1.2 \%) .{ }^{1}$ At present time, India is the third country after China and USA with a large elderly population. Problems related to health, social support, and economic securities are more with elderly people. Their healthcare needs differ from those of the younger group. Although elderly are reported to be responsible for half the total drug usage, less than $5 \%$ of randomized control trials have been designed for them. ${ }^{2}$ The elderly patient group requires the use of multiple medications due to presence of co morbidities which increase the chance of noncompliance, economic burden, adverse drug reactions (ADRs), drug interactions, use of inappropriate medications, and the irrational prescription. ${ }^{3}$ To detect and prevent the problems associated with elderly population a drug utilization study would be an appropriate tool.

Drug utilization study has been defined by the World Health Organization (WHO) in 1977 as "study of marketing, distribution, prescription, and use of drugs in society, with special emphasis on the resulting medical, social, and economic consequences". Drug utilization study may provide insights into different aspects of drug use and drug prescribing, such as pattern of drug use, 
quality of use, determinants of use, and outcome of drug use. $^{4}$ By periodic evaluation of drug utilization and optimizing prescribing, these hurdles in pharmacotherapy can be conquered by forming prescription guidelines for geriatric patients. ${ }^{5}$

Two large cross-sectional, population-based studies: the Melbourne Visual Impairment Project and the Blue Mountains Eye Study conducted in Australia has good epidemiological data concerning eye disease and visual loss. These studies focus on the exponential increase in visual loss with increasing age. ${ }^{6}$

The most common conditions and the principal causes of visual impairment in the elderly are refractive error, cataract, age-related macular degeneration (AMD), diabetic retinopathy and chronic open-angle glaucoma. ${ }^{7}$

\section{Commonly used route of drug administration in ophthalmologic practice are}

- Topical- advantages are high patient compliance, selfadministrable and noninvasive, applied in cases like keratitis, uveitis, conjunctivitis, scleritis, eposcleritis and blepharitis.

- Oral/systemic- advantages are patient compliance and non-invasive route of administration, used for scleritis, episcleritis, retinitis etc. ${ }^{8}$

Hence, to gain insight into the prescribing pattern especially in eye diseases which are a common problem in elderly, so as to identify prescribing related problems, is the fundamental step in improving the quality of prescription and patient care.

\section{METHODS}

A retrospective study was carried out from $1^{\text {st }}$ June 2017 to $30^{\text {th }}$ June 2018 after obtaining approval from the Institutional Ethics Committee. All in-patients case records fulfilling the inclusion criteria of patients admitted for eye ailments in ophthalmology department of the tertiary care hospital were included in the study. The case records were collected from medical records section. A predesigned proforma to study the drug prescribing pattern which contained relevant information such as patient demographics (age, gender), clinical data (symptoms, laboratory findings), treatment data (drugs prescribed generic/brand name, dosage, route, and frequency of administration) was used.

\section{Inclusion criteria}

- All Case records of patients above 60 years of age, with eye related disease as diagnosed by the consultant ophthalmologist.

- All Case records of patients who were admitted in the hospital for more than one day for treatment of eye related disease during the said study period.

\section{Exclusion criteria}

- Case records of patients with incomplete patient/ drug related information.

- Case records of patients referred from another center and the same treatment has been continued.

\section{Prescriptions were analyzed using WHO prescribing indicators}

- Average number of drugs per encounter

- Percentage of drugs prescribed by generic name

- Percentage of encounters with antibiotics

- Percentage of encounters with injections

- Percentage of drugs from essential drug list.

\section{Statistical analysis}

SPSS 17 software package was used for all statistical calculations. Descriptive statistics were used to analyse the data.

\section{RESULTS}

A total of 849 case records were collected. 38 case records were excluded from analysis due to incomplete information of either the patient or drugs. Of the 811 case records thus analysed, 428 were of male patients $(52.77 \%)$ and 383 were of female patients $(47.22 \%)$ (Figure 1).

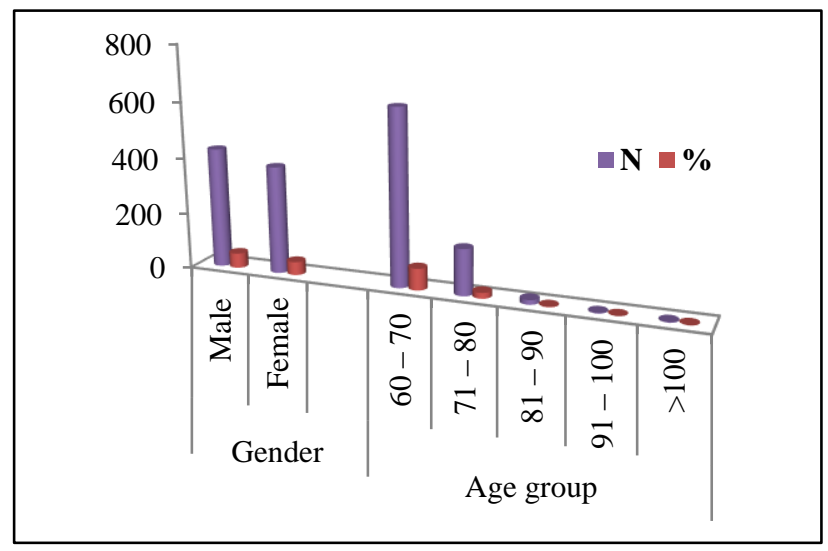

Figure 1: Characteristics of study participants $(\mathbf{n}=811)$.

Cataract $(77.06 \%$ ) was the most common clinical condition noted for which drugs were prescribed in the study population (Figure 2).

A total of 584 prescriptions had oral drugs. The most commonly orally administered drug was Ciprofloxacin 250 $\mathrm{mg}$ accounting to $334(57.1 \%)$ of prescriptions. Other drugs prescribed were benzodiazepine Diazepam 10mg $15.7 \%$ (92), Osmotic diuretic Acetazolamide 250mg $14.7 \%$ (86) and steroid Methylprednisolone $6 \mathrm{mg} / 8 \mathrm{mg}$ $12.3 \%$ (72). 


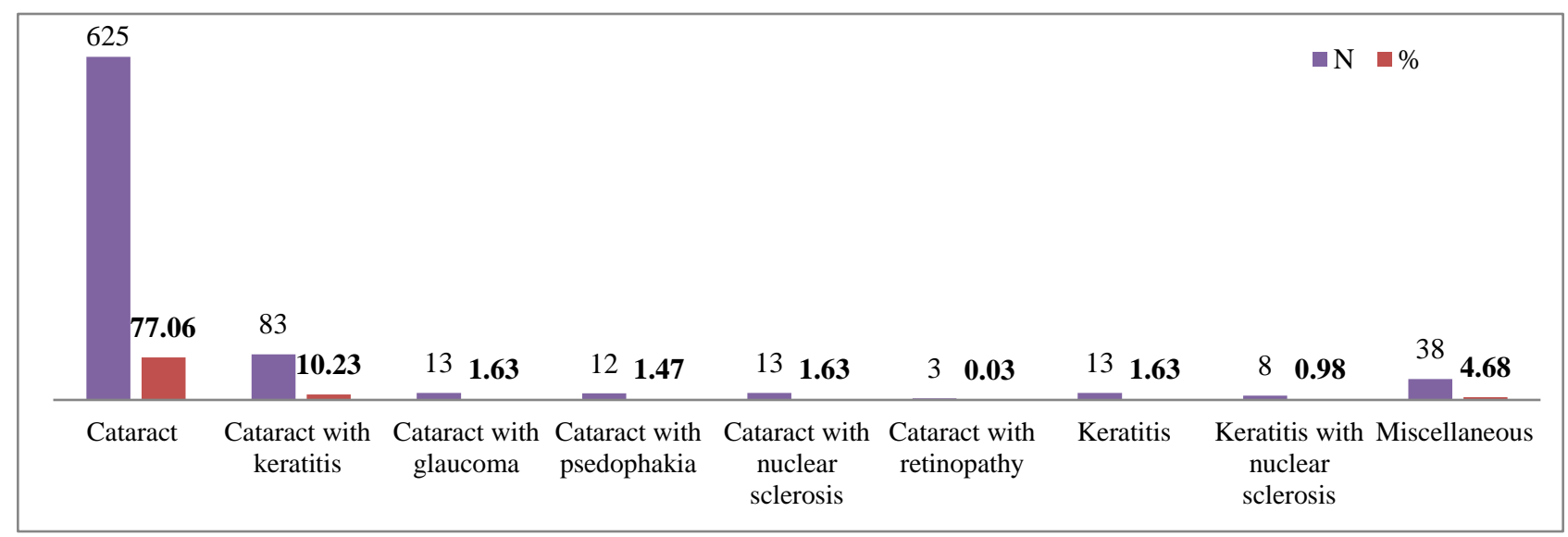

Figure 2: Clinical conditions with number of patients and percentage.

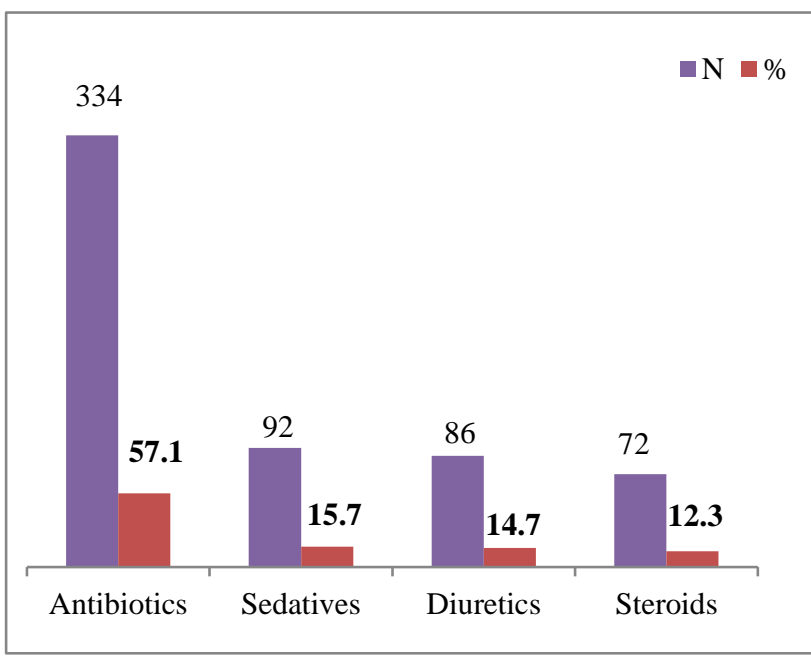

Figure 3: Various groups of drugs (oral) prescribed in the study $(n=584)$.

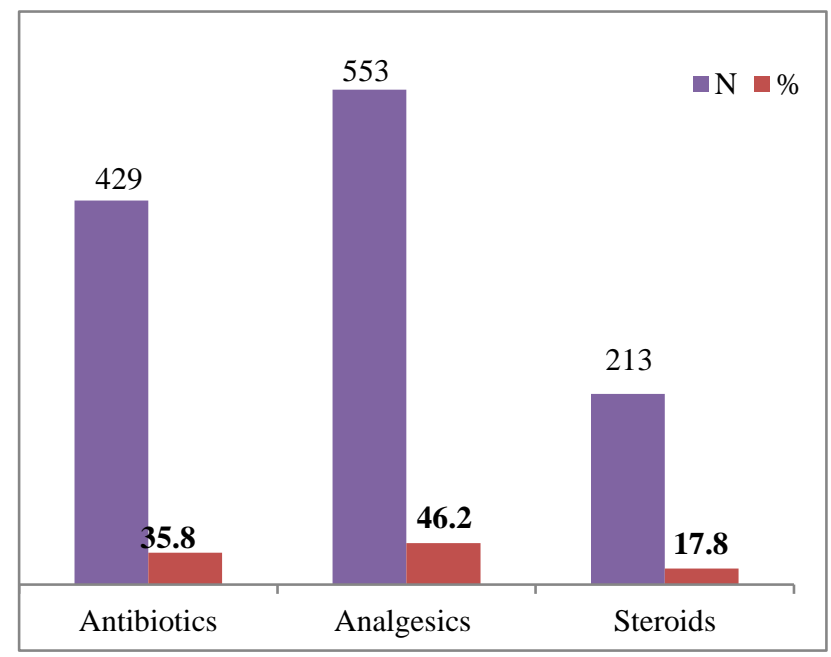

Figure 4: Various groups of drugs (topical) prescribed in the study $(n=1195)$.

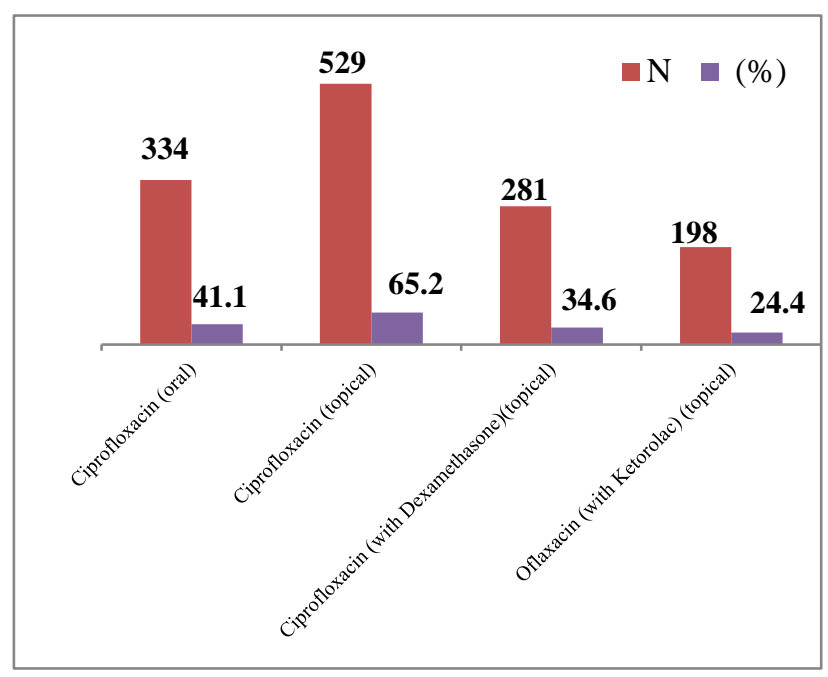

Figure 5: Various antibiotics prescribed in the study population $(\mathrm{n}=811)$.

The number of drugs used topically as eye drops were 1195 , common group to be prescribed was of analgesics (46.2\%) (Flubiprofen $5 \mathrm{ml}$ [553] and Ketorolac $5 \mathrm{mg}$ [198]). Topical antibiotics used were Ciprofloxacin 0.3\% $44.2 \%$ (529), Ciprofloxacin 0.3\% + Dexamethasone 0.1\% - 34.6\% (281), and Ofloxacin 3mg 24.4\% (198) and steroids (Prednisolone $1.0 \% \quad 17.7 \% \quad$ [212] and Dexamethazone $0.1 \% 34.6 \%$ [281]) (Figure 3 and 4).

All case records exhibited the prescriptions of FDCs $(100 \%)$ to the patients. The three FDCs used were Ketorolac $5 \mathrm{mg}+$ Ofloxacin $3 \mathrm{mg}$, Tropicamide $0.8 \%+$ Phenylephrine $5 \%$ and Ciprofloxacin $0.3 \%+$ Dexamethasone $0.1 \%$, as shown in the Table 1 .

Rationality of prescriptions was assessed using WHO core prescribing indicators, values of which are presented in Table 2. 
Table 1: Group of FDCs prescribed in the study $(n=811)$.

\begin{tabular}{|llll|}
\hline Prescribed FDCs & Number of FDCs N (\%) & Rational FDCs N (\%) & FDCs in EML N (\%) \\
\hline Ketorolac 5 mg + Ofloxacin 3mg & $198(24.4)$ & 100 & Nil \\
\hline Tropicamide 0.8\% + Phenylephrine 5\% & $703(86.6)$ & 0 & Nil \\
\hline $\begin{array}{l}\text { Ciprofloxacin 0.3\% + Dexamethasone } \\
0.1 \%\end{array}$ & $281(34.6)$ & 100 & $281(34.6)$ \\
\hline
\end{tabular}

Table 2: The prescriptions assessed using WHO core prescribing indicators $(n=811)$.

\begin{tabular}{|lll|}
\hline Prescribing indicators & Total drugs/encounters & Average/percentage \\
\hline Average number of drugs per encounter & 3057 & 3.7 \\
\hline Percentage of drugs prescribed by generic name & 61 & 2 \\
\hline Percentage of encounters with antibiotics & 1342 & 43.8 \\
\hline Percentage of encounters with injections & 0 & 0 \\
\hline Percentage of drugs from essential drug list & 1864 & 60.9 \\
\hline
\end{tabular}

\section{DISCUSSION}

After screening of 811 prescriptions, it was found that there was no significant gender preponderance (male $52.77 \%$ and female $47.22 \%$ ) of eye diseases among the geriatric patients. The eye ailments were found to be more in the age group of $60-70$ years. These findings prove that the eye diseases are usually not gender linked but may be age related.

Around $77.06 \%$ of diagnosis accounted for cataract alone while $14.99 \%$ accounted for cataract with other associated diseases like keratitis, glaucoma, pseudophakia, nuclear sclerosis and retinopathy, $4.68 \%$ patient records were with diagnosis miscellaneous eye disorders like pterygium, post operative endophthalmitis, chronic dacryocystitis, iris prolapse, etc.

These findings confirm that one of the significant health care problem related to the human eye is cataract as seen in the statistics in all parts of the world. It leads to blindness if untreated and still remains the most prevalent cause of blindness globally in spite of an effective treatment. ${ }^{9} \mathrm{~A}$ similar trend of age related cataract was noted in our study population also.

Empirical treatment in eye conditions is based on the likely etiology, the available medical treatment and the surgical treatment. Patients were treated with various drugs in different dosage forms and ongoing medical treatment was modified according to clinical response and the most common drugs prescribed were mydriatics, antibiotics, sedatives, diuretics, steroids and analgesics. The higher use of antibiotics reflects the condition of poor sanitation, nutrition, prevalence of various infections, post operative infection and certain acute infective conditions which needs conservative management. Use of analgesics was to overcome pain and swelling and mydriatics were used for fundus examination, surgery and for conservative management of the particular disease. Hence, the eye care providing health professionals need to focus on counselling and informing patients of preventive measures related to eye hygiene and good nutrition habits to curb the common preventable eye infections.

Some FDCs were prescribed in the study and it was found that ketorolac $5 \mathrm{mg}+$ ofloxacin $3 \mathrm{mg}$ and ciprofloxacin $0.3 \%$ + dexamethasone $0.1 \%$ were rational and only ketorolac is not included in WHO EMLc. However, tropicamide $0.8 \%+$ phenylephrine $5 \%$ were found to be irrational and Phenylephrine is not included in the WHO EMLc. Combination of ciprofloxacin $0.3 \%$ and dexamethasone $0.1 \%$ eyedrops is effective in controlling inflammation after cataract surgery. ${ }^{10}$ Tropicamide $0.8 \%$ and phenylephrine 5\% using two drops less for one eye can save a large financial burden especially in an average eye hospital. ${ }^{11}$ These careful conclusions need to be noted and made use of by the ophthalmologists and irrational FDC use has to avoided. Different antibiotics used were ciprofloxacin (oral 41.1\%, topical $65.2 \%$, with dexamethazone topical $34.6 \%$ ) and oflaxacin (with ketorolac) topical $24.4 \%$ were used. A few studies report that minimum inhibitory concentrations of the fluoroquinolones against ocular pathogens acknowledge that ciprofloxacin is more potent than ofloxacin against many bacteria. ${ }^{12}$

In this study, it was found that most prescriptions conformed to WHO core drug prescribing indicators except percentage of encounters with injections as there was no injection were used.

Some of the limitations of this study were that it was conducted in a single center and results may not be applicable to general population, study evaluated drug use pattern only from the inpatients and prescription pattern may vary among OPDs patients. WHO core drug prescribing indicators only indicate quantity of drugs 
prescribed but cannot determine accuracy of diagnosis or adequacy of drug choices. Furthermore, patient care indicators and facility indicators were not included as this was a prescription-based study. However, it provides useful baseline data over which future studies can be built upon. Drug prescriptions form a very important point of contact between the health care provider and the user. ${ }^{13}$ It provides an insight into the nature of health care delivery system and is a reflection of physician's attitude towards the disease and the role of drug in its treatment. ${ }^{14}$ Average number of drugs per prescription is an important index of prescription audit. Historically the pharmaceutical and medical professions have devoted considerable time and efforts to the development and rational utilization of safe and effective drugs for the treatment and prevention of illness. There has been development of many new therapeutic agents which have made it possible to cure or provide the symptomatic control of many clinical disorders. However, in many circumstances' drugs are not used rationally for optimal benefits and safety. ${ }^{15}$

Therefore, drug utilization studies can be a powerful tool that can benefit patient and public health but only if used appropriately by providing the insights into various aspects of drug prescribing and drug uses. WHO organizes many drug utilization researches with the goal of rational prescription by various methods of audit. This study was also a part of prescription audit. Prescription audit is a quality improvement process that seeks to improve patient care. Regular prescription audit is important for health care professionals and managers, patients, and the public also supports the health professionals in making sure the patients receives the best care. ${ }^{16}$

\section{ACKNOWLEDGEMENTS}

Authors are thankful to the management of the SDM College of Medical Sciences and the personal of medical record section for all the help extended during the study.

Funding: No funding sources

Conflict of interest: None declared

Ethical approval: The study was approved by the Institutional Ethics Committee

\section{REFERENCES}

1. Chanana HB, Talwar PP. Aging in India: Its Socio-economic and health implications. Asia Pac Popul J. 1987;2(3):23-38.

2. Zaveri HG, Mansuri SM, Patel VJ. Use of potentially inappropriate medicine in elderly: A prospective study in medicine outpatient department of a tertiary care teaching hospital. Indian J Pharmacol. 2010;42(2):95-8.

3. Gorzoni ML, Fabbri RM, Pires SL. Potentially inappropriate medications in elderly. Rev Assoc Med Bras. 2012;58(4):442-6.
4. World Health Organisation. Introduction to drug utilization research. Geneva: World Health Organisation; 2003. Available at: https://www.who.int/entity/medicines/areas/quality_s afety/safety_efficacy/utilization. Accessed 8 February 2019.

5. World Health Organization. Introduction to drug utilization research. Oslo: World Health Organization; $2003 . \quad$ Available at: https://www.who.int/medicines/areas/quality_safety/s afety_efficacy/Drug\%20utilization\%20research.pdf? ua $=1$. Accessed 8 February 2019

6. Taylor HR, Keefe JE, Vu HTV, Wang JJ, Rochtchina E, Pezzullo ML, et al. Vision loss in Australia. Med J Aust. 2005;182(11):565-68.

7. Green C, Goodfellow J, Kubie J. Eye care in the elderly. Aust Fam Physician. 2014;43(7):447-50.

8. Gaudana R, Ananthula HK, Parenky A, Mitra AK. Ocular drug delivery. AAPS J. 2010;12(3):348-60.

9. Kessel L, Haargaard B, Boberg-Ans GE, Henning VA. Time trends in indication for cataract surgery. Clin Experimen Ophthalmol. 2011;2(7):1-4

10. Mohan N, Gupta V, Tandon R, Gupta SK, Vajpayee RB. Topical ciprofloxacin-dexamethasone combination therapy after cataract surgery: randomized controlled clinical trial. J Cataract Refract Surg. 2001;27(12):1975-78.

11. Jethani J, Solanki H, Nayak A. Effect of the singledrop mydriatic combination of $0.8 \%$ tropicamide with $5 \%$ phenylephrine with multiple applications of the same drop: A randomized controlled trial. Indian $\mathbf{J}$ Ophthalmol. 2011;59(4):323-5.

12. Diamond JP, White L, Leeming JP, Hoh HB, Easty DL. Topical $0.3 \%$ ciprofloxacin, norfloxacin, and ofloxacin in treatment of bacterial keratitis: a new method for comparative evaluation of ocular drug penetration. Br J Ophthalmol. 1995;79(6):606-9.

13. Nehru M, Kohli K, Kapoor B, Sadhotra P, Chopra V, Sharma R. Drug utilization study in outpatient ophthalmology department of government medical college, Jammu. JK Sci. 2005;7(3):149-51.

14. Shankar PR, Upadhyay DK, Subish P, Bhandari RB, Das B. Drug utilization among older inpatients in a teaching hospital in Western Nepal. Singapore Med J. 2010;51(1):28-34.

15. Hussar DA. Patient compliance. In: Remington: the Science and Practice of Pharmacy, 19th ed, eds. Gennaro AR, Chase GD, Marderosian AD, et al. Easton, Pennsylvania, Mack Publishing Company;1995:1796-1806.

16. Panayappan L, Jose JM, Joseph JG, Jayapal K, Sahu S, Krishnakumar K Prescription Audit and Prescribing Indicators: A Review J Bio Innov. 2017;6(4):542-47.

Cite this article as: Prathap SA, Radhika MS, Rai RK. Prescribing pattern of ophthalmological medication in geriatric inpatients of a tertiary care hospital. Int J Basic Clin Pharmacol 2019;8:940-4. 